\title{
Berberomeloe, Real Olive Oil
}

\author{
García Segura Florence* \\ Faculty of Medicine, Veterinary, Zoo, Benemérita Autonomous, University of Puebla, Mexico \\ *Corresponding author: García Segura Florence, Faculty of Medicine, Veterinary, Zoo, Benemérita Autonomous, \\ University of Puebla, Mexico
}

\section{ARTICLE INFO}

Received: 㗀 June 04, 2020

Published: 慧 June 19, 2020

Citation: García Segura Florence. Berberomeloe, Real Olive Oil. Biomed J Sci \& Tech Res 28(3)-2020. BJSTR. MS.ID.004644.
ABSTRACT

They have no defensive system, their black and red colors warn their predators of their bad taste. When defending, they secrete a blood-red hem lymphatic substance, called cantharidin, which is very irritating to the touch. Adult size varies widely, from 15 to $75 \mathrm{~mm}$ [1]. Singharidin is excreted along with its blood (hemolymph) through lateral holes when it feels attacked or in danger. This reddish liquid if touched causes a burning sensation like that produced by boiling oil on the skin, hence its vulgar or common name. This substance is known as cantharidin which causes redness, rashes and irritation on contact with the skin. If you have oral contact, it causes nausea, vomiting, diarrhea and irritation in the urinary system and causes the erection of the penis, which is why it was previously considered an aphrodisiac substance. The signs that appear are: Five minutes after the poison deposit, edema begins, erythema; whitish spot at the site of the poison deposit. After fifteen minutes, the ampules accentuate their size; Later it appears, dizziness, hypertension, tachycardia, vomiting.

Description or characteristics

Animalia Kingdom

Edge: Arthropoda

Insecta class

Order: Coleoptera

Family: Meloidae

Subfamily: Meloinae

Tribe: Lyttini

Genre: Berberomeloe Species: B. insignis, B. majalis

Animal type: Beetle [2,3].

\section{Mini Review}

They are arthropods of the insect class of the order Coleoptera and of the family Meloidae. Within the arthropod biodiversity in Mexico we can find endemic species of Eurasian, Mediterranean, Atlantic, North African and endemic origin. Its common name is oil or curica. There are two species: Bermeromeloe majalis and Berberomeloe insignis. B. majalis has a head of rounded temples of total black color, it may include a reddish or orange transverse band below each abdominal tergite. Berberomeloe insignis its temples are more prominent, red in the temples, it has no color in the abdominal region. B. insignis is more than $8 \mathrm{~cm}$, total black with red or orange temples. Its antennae are shaped like saws with a quadrangular pronotum with a smooth surface. It is a walking beetle, it cannot fly and it makes it easier to run over it on highways and roads. Throughout history they have been given various uses: cleaning and healing of wounds infected or with myiasis, until their use as an abortifacient and powerful aphrodisiac, perhaps the latter the best [4-6].

In their biological cycle, the imagos appear between March and May, their preferred plants are: thyme, rosemary, albaida, rockrose. Many of these beings make poison their secret weapon, warning the world of its toxicity thanks to the presence in their bodies of thorns, stingers or bright colors [7]. They have no defensive system, their black and red colors warn their predators of their bad taste. When defending, they secrete a blood-red hemolymphatic 
substance, called cantharidin, which is very irritating to the touch. Bermeromeloe majalis and Berberomeloe insignis have mitochondrial DNA. Both are in a state of disappearance, due to the expansion of agricultural areas, use of pesticides, herbicides, human habitat. Its venom is a powerful biocide, causing great impacts on the group of insects in general, having been able to reduce bee colonies by $40 \%$ worldwide [4], due to the intimate relationship it has Berberomeloe majalis with the Order Hymenoptera, due to the aforementioned obligate parasitoid habit developed by the larva, and which is essential to complete its biological cycle, makes it necessary to study this potential relationship. Adult size varies widely, from 15 to $75 \mathrm{~mm}$ [5].

\section{Distribution}

Some authors mention that it is found throughout the Iberian peninsula, others indicate that it is distributed to the Southeast of the Iberian Peninsula in regions of altitude of 3000-900 masl, in semi-arid areas [5].

\section{Anatomy}

The female has an elongated and fusiform black abdomen. Head and thorax poorly developed compared to the abdomen. With transverse bands of red-yellow-orange color, on the back of each abdominal segment. This coloration may be absent, so uniform black species can be observed. Short antennas formed by
11 spheroidal knuckles. Head and thorax thickly dotted. Dotted elytra and much shorter than the abdomen, which is almost completely exposed. They have no wings. Bermeromeloe majalis and Berberomeloe insignis present a metamorphosis process in which two or more different types of larvae participate, it is known as hyper metamorphosis. In this case it behaves like a parasitic species. When the female lays eggs, she helps with her legs and body to make a shallow hole in the ground. At the beginning of the summer the first larvae, of small size, come to the surface and look for flowering plants to which they climb to locate in the corolla of a flower. This elongated larva has three strong nails at the end of each leg, for this characteristic they are called triungulinus. These nails allow a great grip on any insect that stands on the flower, especially by the solitary bee or by another insect such as serphids and bumble bees. For this reason they lay hundreds of eggs. If the Bermeromeloe majalis and Berberomeloe insignis larva is capable of supporting itself to be transported by the appropriate solitary bee to its nest or honeycomb, it will have completed the most complicated part of the oiler cycle. The body of the new larva is fuller and larger, and will feed on the pollen stored by the solitary bee, in the nest or honeycomb. Upon reaching the pupal stage, it will take time for the person to become an imago or an adult. These appear from April to May, being from June in areas with higher altitudes, such as Sierra Nevada (Figures 1-3).
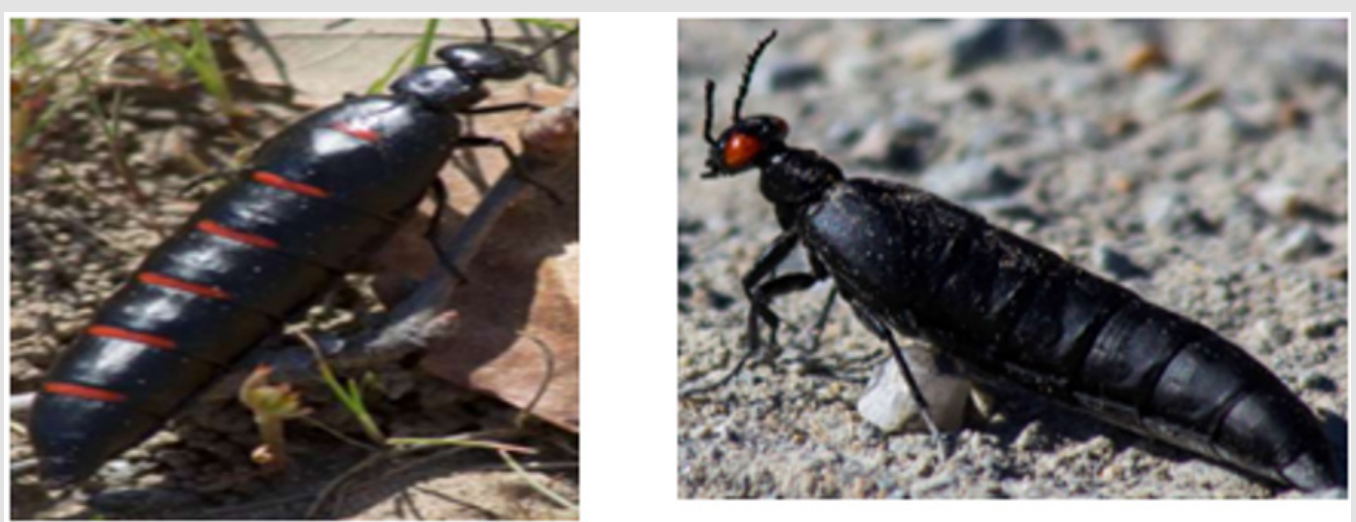

Figure 1.

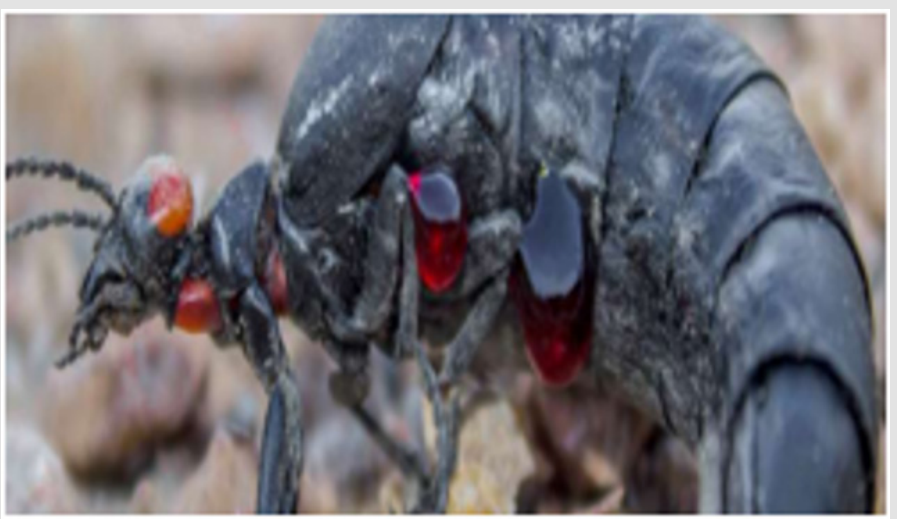

Figure 2: B. insignis Hemolymphatic red discharge. 


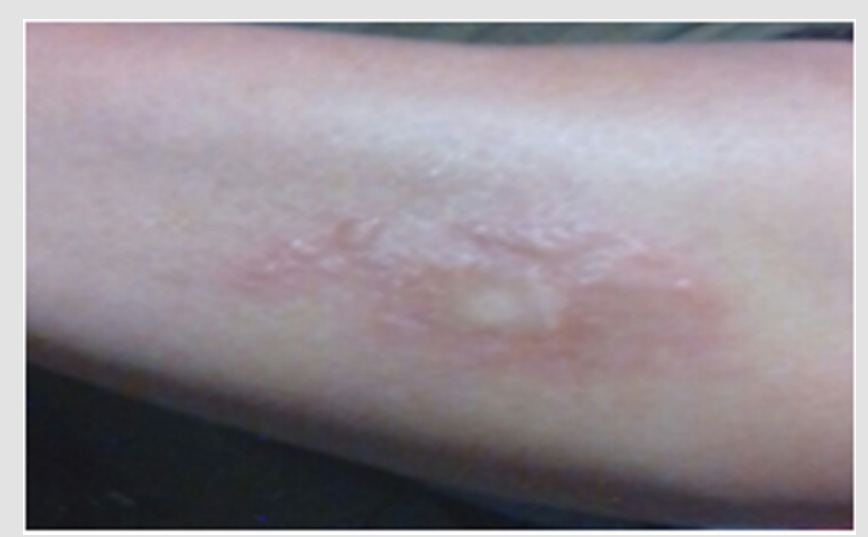

Figure 3: Five minutes after the deposition of the venom, onset of edema, erythema; whitish spot in place of the poison deposit.

\section{Habitat}

Its habitat is in a semi-arid zone, with low precipitation, with shrubby vegetation, where there are no trees; prefer dry areas in summer with sparse vegetation and close to forested areas and rural habitats. In Spain it lives from the Iberian Strip from the south, Granada, Almería and Murcia. Lives in carbonated soils, loams, limestones and dolomites, yesiferous and subsalt loams. But these habitats tend to gradually disappear and this beetle is on the list of the Red Book of invertebrates in Spain, Andalusia [5].

\section{Feeding}

In the larval phase they feed on adults and eggs of hymenoptera: bees and wasps. Once inside the nest, the larva feeds on a bee pupa and occupies the corresponding cell. From this moment it feeds on nectar and pollen given by the solitary bee. When growing it forms a pseudopupa that after a time gives rise to a second larva with a very different morphology from the previous one. In the adult phase it consumes flowers and leaves of plants.

\section{Reproduction}

Berberomeloe insignis has uninvolving phenology (they complete a single life cycle throughout the year), during the day they are more active in the months of March - May. The male courtship for the female, which consists of chasing her next to her abdominal apex, then she proceeds to dig a hole to lay her eggs. When hatching the eggs they look for Apoidea nests to feed.

\section{Poison Composition}

There are no differences in the amount of cantharidin produced by species with and without rays. She has cantharidin that she excretes with her blood (hemolymph) through lateral holes when she feels attacked or in danger. This reddish liquid if touched causes a burning sensation like that produced by boiling oil on the skin, hence its vulgar or common name. As a defense mechanism, Berberomeloe majalis exudes a few drops of an oilylooking substance (hence the popular name for oil cans), which is very toxic and irritating, especially if it comes into contact with the mucosa and eyes. This substance is known as cantharidin, which causes redness, rashes and irritation on contact with the skin. If it is consumed orally, it causes nausea, vomiting, diarrhea and irritation in the urinary system and causes the erection of the penis, which is why it was formerly considered an aphrodisiac substance. For this reason this species presents these warning colors, also called aposematics. The royal oil poison is used to eliminate warts, the body of these insects is stored in olive oil to be applied in blister or vomiting pustules, diarrea. High toxicity chemical compound found in its hemolymph, called cantharidin, vesicant on contact and potentially fatal, due to the powerful nephrotoxic effects caused by its intake, possessing an estimated LD50 of $0.03 \mathrm{~g} / \mathrm{Kg}[2,6]$.

\section{Symptoms and Signs}

When threatened, it secretes a substance that resembles an oily liquid called cantharidin with its length of more than $6 \mathrm{~cm}$, it is extremely toxic. One of the most remarkable characteristics of these insects is their defensive system based on a highly toxic chemical compound found in their hemolymph, called cantharidin, vesicant on contact and potentially fatal, due to the powerful nephrotoxic effects caused by their ingestion. Possessing an estimated LD50 of $0.03 \mathrm{~g} / \mathrm{Kg}[1,2]$. This characteristic is well known in popular culture $[7,8]$.

\section{Clinical case / Treatment}

Finally, to finish, it should be noted that the vesicant effect produced by specimens of this species in relation to its contact with people's skin has also been verified. Thus, approximately ten hours after we accidentally sat down on a specimen of this species and without proceeding to wash the area in contact with the hemolymph that pierced all the garments until reaching the skin, the appearance of bladders was observed in it of significant magnitude accompanied by significant local pain. This effect is probably the one that should be sought in the treatment with animals, since prolonged contact probably produces an effect similar to that of cauterization, it is capable of piercing clothing and causing serious injury in the contact area (Figures 4-7). 


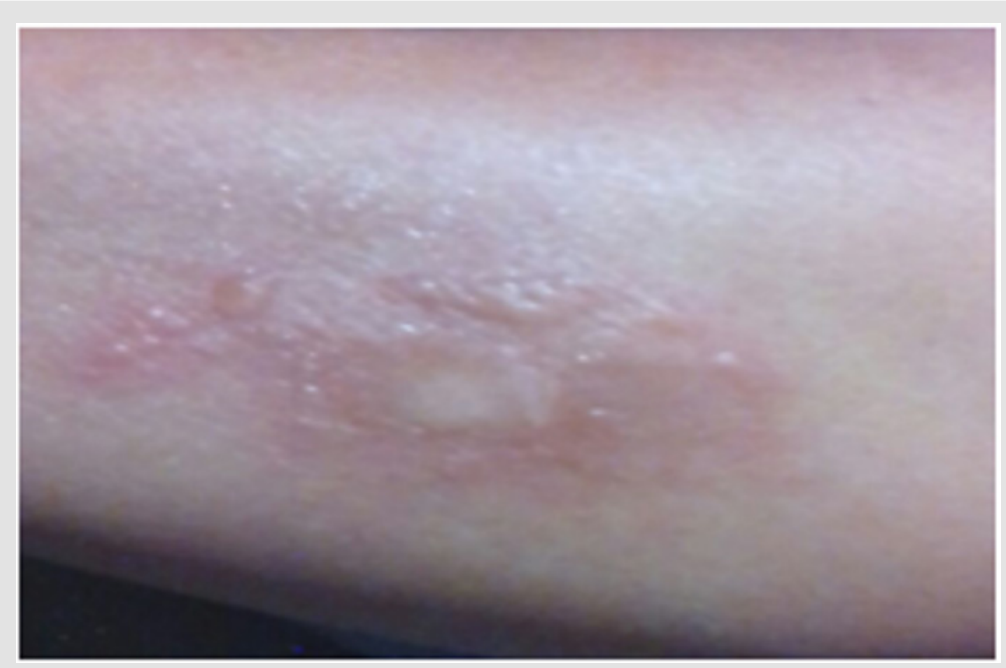

Figure 4: After fifteen minutes, the ampules accentuated their size. He was in a lot of pain and went to the Hospital for medical attention. He presented with dizziness, hypertension, tachycardia, vomiting.

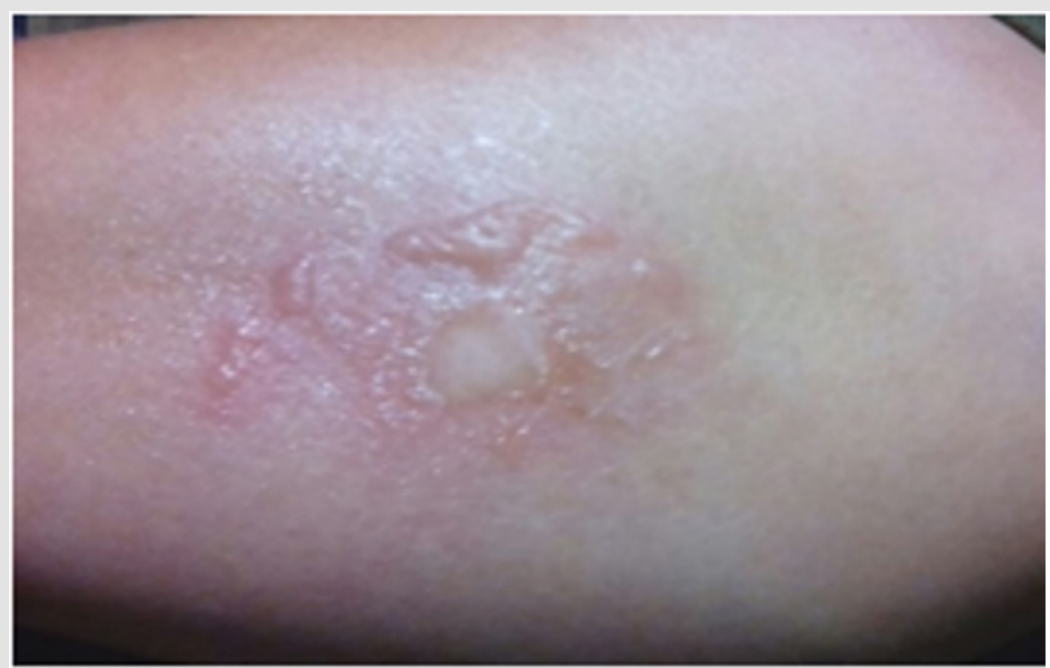

Figure 5: Five hours, the pain much like a burn increased. They applied dermatological cream and methylene blue to disinfect.

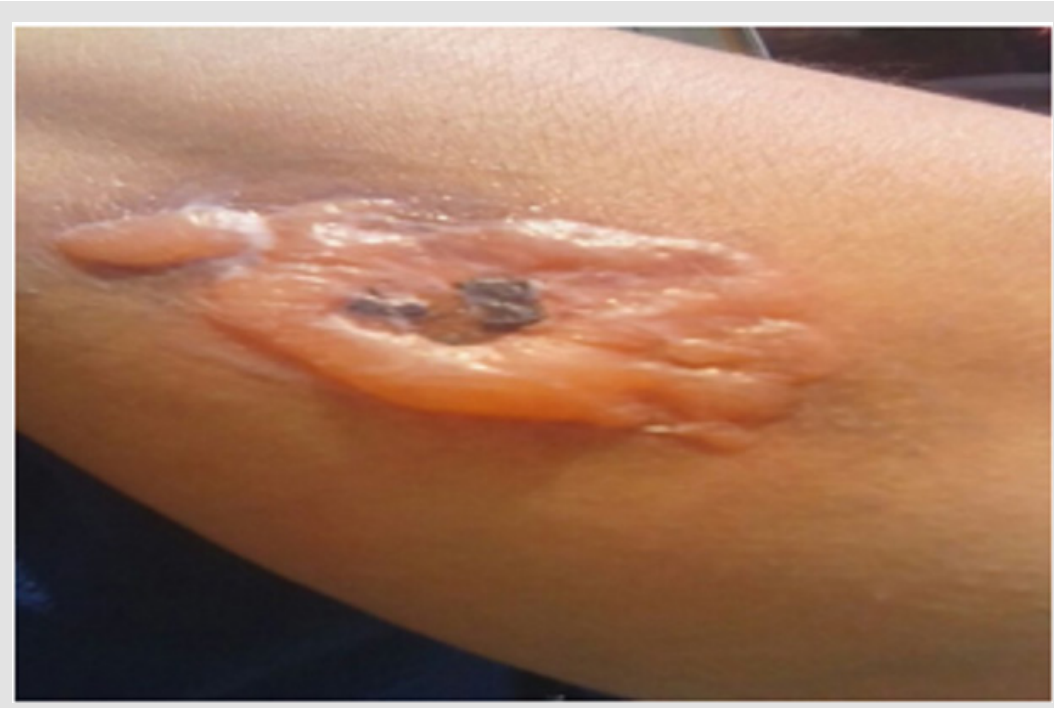

Figure 6: 12 hours later the ampules were joined and the puffiness of the affected area spread. 


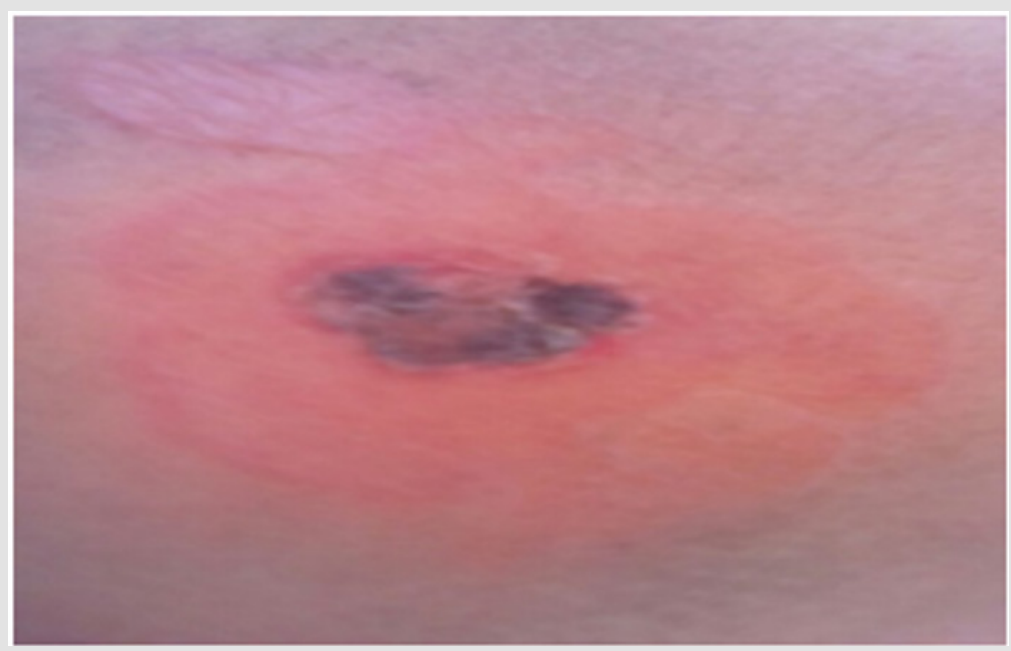

Figure 7: Two weeks after the cantharidin deposit, necrotic tissue is observed in the center and perpetuates the erythema in the peripheral area of the lesion. The area became very sensitive after several weeks.

\section{Clinical Case}

MVZ Enrique Gonzaga, was cutting corn fodder, to feed his cows, it was 12 o'clock one morning, he was wearing a shortsleeved shirt, suddenly he observed that a black worm deposited on his arm, under the elbow joint a red liquid. He did not care, because he had seen that he did not bury any stinger. The signs and injuries are as follows.

\section{Prevention}

a) If you encounter them, do not touch them directly with your hand.

b) If you go to the field, wear a hat and a thick long-sleeved shirt.

c) Do not walk barefoot.

d) Mow the grass near the house-room.

e) Be careful when cutting wildflowers, because the larvae may be in them.

\section{References}

1. Bergillos F, Riva SMA (2013) Animal Stings and Bites: Treatise on Clinical Toxinology. In Bergillos F, Riva SMA (Eds.), Bubok Publishing SL, UK I: 978-84-686-3692-4.

ISSN : 2574-1241

DOI: $10.26717 / B J S T R .2020 .28 .004644$

García Segura Florence. Biomed J Sci \& Tech Res

This work is licensed under Creative Commons Attribution 4.0 License

Submission Link: https://biomedres.us/submit-manuscript.php
2. Bologna MA (1988) Berberomeloe, a new west Mediterranean genus of Lyttini for Meloe majalis Lineé (Coleoptera, Meloidae). Systematics and bionomics. Italian Journal of Zoology 55(1-4): 359-366.

3. Cortés Fossati, Fernando, Cervera Currado, Juan Lucas (2018) Berberomeloe majalis (Linnaeus, 1758), one of the largest beetles in Europe present in the Campo de Gibraltar. Contribution to its ethology, distribution and traditional uses in the province of Cádiz. Almoraima. Magazine of Campogibraltareños Studies, 49 Algeciras. Instituto de Estudios Campogibraltareños 49: 47-54.

4. Culma M, Yolieth N (2017) Evaluation and Effects of Pesticides on Bees: Current Situation and Regulations in Colombia (Doctoral dissertation).

5. García París MJL, Ruiz (2008) Berberomeloe insignis (Charpentier, 1818). In Barea Azcón JM, Ballesteros Duperón E, Moreno D (Eds.), Red Book of the Invertebrates of Andalusia. Ministry of Environment. Junta de Andalucía. Seville 4: 1020-1029.

6. García Paris M, Ruiz LJ, Percino DN, Buckley D (2016) Common names of the oil-fleshed and oil-filled (coleoptera: meloidae) of Spain: circumstances compel. (SEA) 58: 245-252.

7. Ghoneim K (2013) Cantharidin toxicosis to animal and human in the World: A review. Standard Research Journal of Toxicology and Environmental Health Sciences 1(1): 1-16.

8. Percino Daniel N, D Buckley, M García París (2013) Pharmacological properties of blister beetles (Coleoptera: Meloidae) promoted their integration into the cultural heritage of native rural Spain as inferred by vernacular names diversity, traditions, and mitochondrial DNA. Journal of Ethnopharmacology 147(3): 570-583.

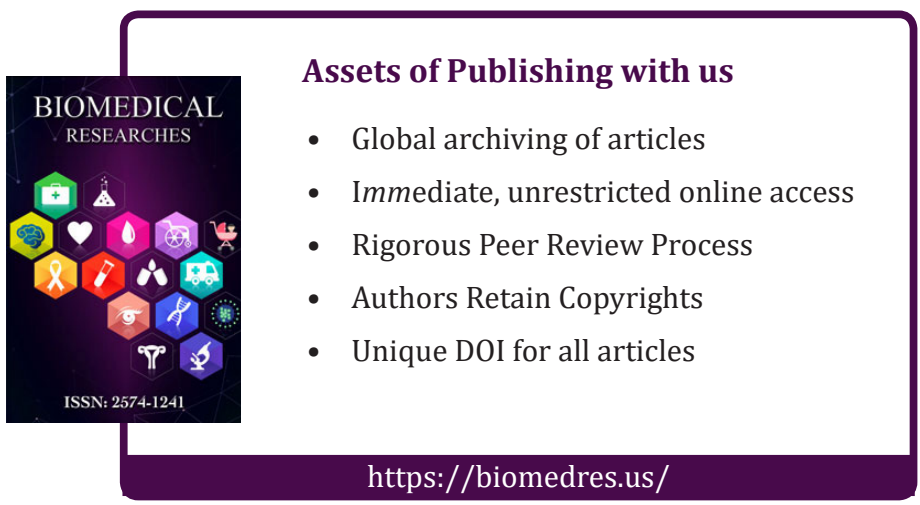

